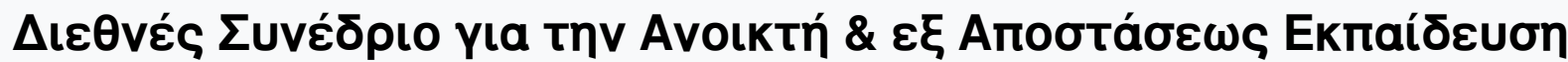

Tón. 8, Ap. 4B (2015)

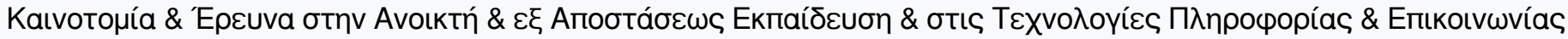

| Пракuiká

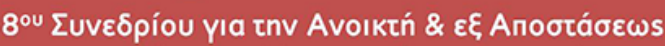

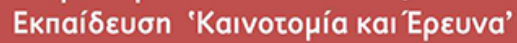

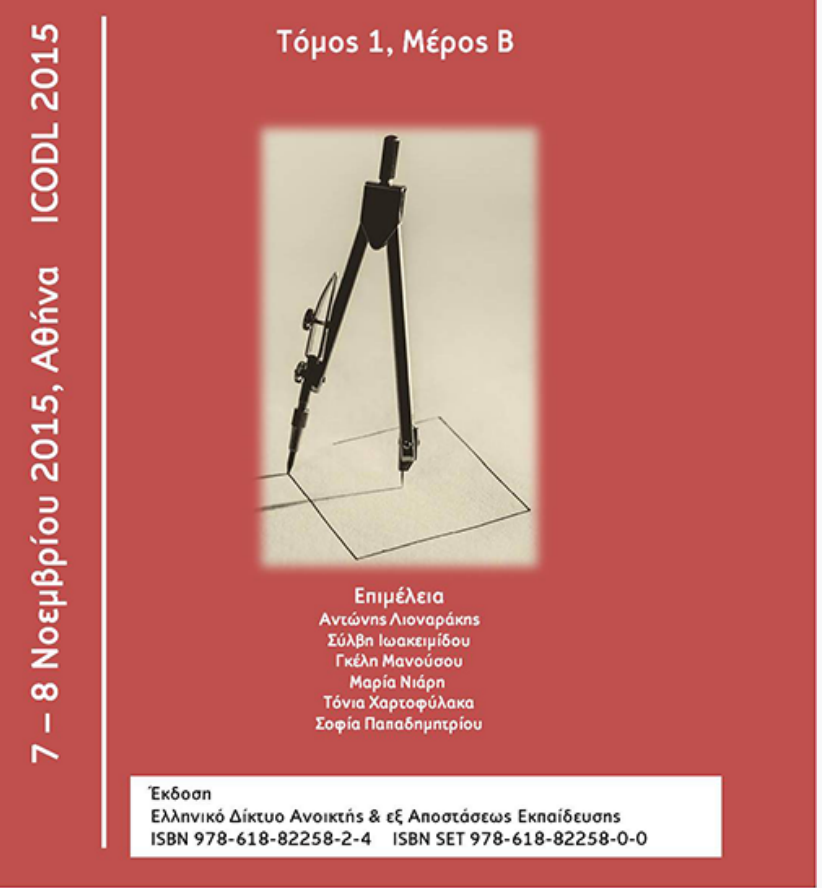

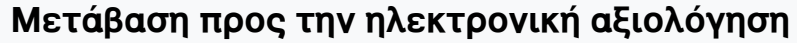

Antonios Andreatos

doi: $\underline{10.12681 / \text { icodl. } .77}$ 


\title{
6 ways towards e-assessment
}

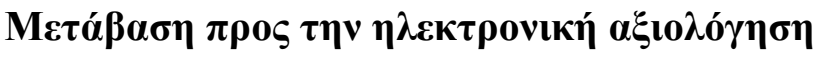

\author{
Andreatos Antonios \\ Div. of Computer Hellenic Engineering and Information Science \\ Hellenic Air Force Academy \\ Dekeleia Air Force Base \\ Dekeleia, Attica, TGA-1010, Greece \\ aandreatos.hafa@haf.gr, aandreatos@gmail.com
}

\begin{abstract}
In this paper we propose six ways to facilitate e-assessment and exam grading. Some of these ways may be applied to a wide variety of subjects while others are more appropriate for engineering courses. The key feature of these ways is that they are appropriate for distance learning, e-learning, as well as, blended learning settings, where machine grading plays an important role, especially when the number of learners is large, as is the case with MOOCs. In this paper we propose some practical ways to teachers wishing to use e-assessment in their educational practice.
\end{abstract}

Key-words: e-learning, blended learning, e-assessment, MOOCs.

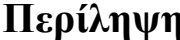

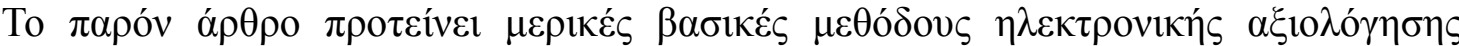

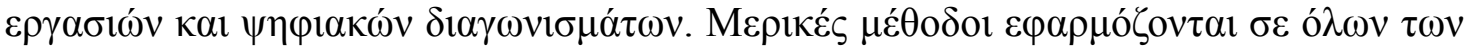

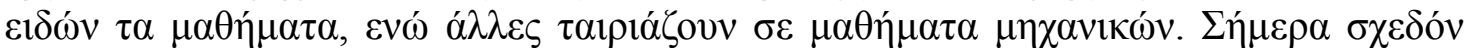

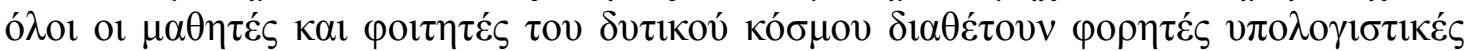

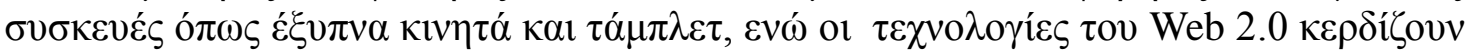

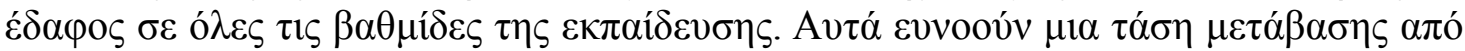

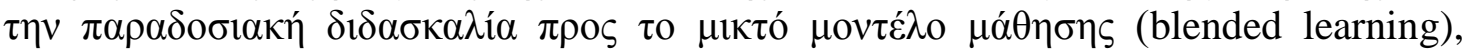

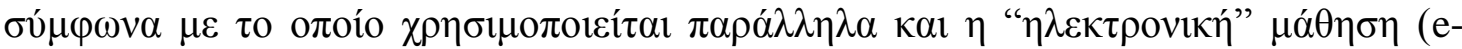

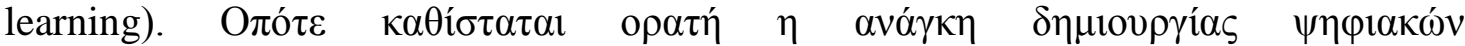

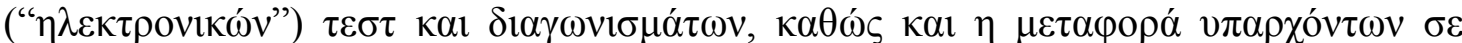

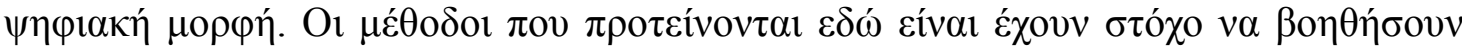

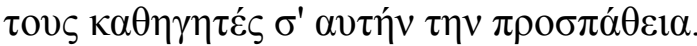

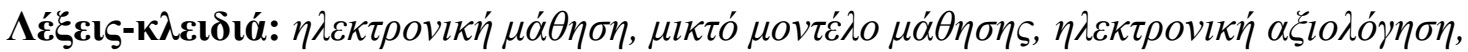

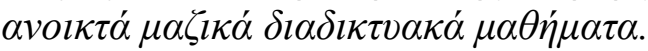

\section{The importance of assessment}

Educational assessment is the process of documenting, usually in measurable terms, knowledge, skill, attitudes or beliefs. Assessment is key to learning because it guides students in their study. Assessment is much more crucial in distance learning and elearning environments where learners study on their own. Learning activities must promote feedback and feed-forward assessment, which helps students to reflect on and improve their learning outcomes. 
Feedback is a vital part of education. It can be effective in promoting learning if it is timely, personal, manageable, motivational, and closel related to the course objectives. However, research suggests that a number of students do not value feedback primarily for reasons that relate to lack of motivation and difficulty in interpretation of the feedback comments (Hatziapostolou and Paraskakis, 2009).

The traditional educational experience uses testing for a number of reasons (Henderson, 2003):

- To let the student know what he/she already knows before taking a class;

- To let the student know what he/she learned after taking the class;

- To the the student's managers know whether the student learned the material, gained a specific skill or adopted a specific attitude.

Tests come in two basic varieties, called pretests and posttests:

Pretests (Before the Class)

- Can be used to let students "test out" of a class. If you can show you know the material, you can get credit as if you had taken the class.

- Can be used to set the baseline of knowledge from which the student begins.

Posttests (After the Class, or After a Part of the Class)

- Can be used to show the student how much has been learned. As a self-check, the student can be told, for example, "If you didn't get 8 out of 10 answers right, you should go back through the material again".

- Can be used as a gate to further progress. If the student doesn't get 8 of 10 right for part one of the class, he/she student can't proceed to part two.

- Can be used to report to management which students passed the tests.

Assessment is closely related to feedback. Feedback is a key educational practice in learning. It typically involves a student receiving corrective comments, either formal or informal, on his or her performance on various tasks, usually exams, by the teacher or peers.

\section{The benefits of e-assessment}

Tests are frequently delivered using computers, either locally or over the Internet. The student can go to a Web page, fill in the test answers, and get the results of the test immediately. Results of the test can be shown to the student, stored for later reporting to management, or both [The E-Learning Question and Answer Book]. The use of computers within the assessment process is called e-assessment. E-assessment is defined as the use of electronic technologies to support student assessment. Eassessment should encourage the rethinking of curriculum, objectives and e-learning technology. E-assessment should also support the measurement of higher order thinking, social skills and group work through means such as digital portfolios.

E-assessment offers a large benefit to the examiner since the marking is all carried out automatically and the results are available as soon as the examination is over. It is also possible to offer instant feedback [Hatziapostolou and Paraskakis, 2009]. Thus, eassessment offers a large benefit to the students as well, since they can obtain their marks at any time during the examination. Since every submission is recorded, it is possible to perform later analyses of the detailed responses to individual questions (Farrow and King, 2008).

The next big advantage of e-assessment concerns massive learning: without computer support, the delivery of MOOCs to thousands of learners would have been impossible. MOOCs use Learning and Content Management Systems (LCMS) to deliver content, 
announcements and quizzes to students, as well as, to perform e-assessment, offer feedback and keep student records (wikipedia: LMS).

E-assessment has even more advantages but from these let us mention reusability and portability. Reusability enables instructors to reuse their assets (being lectures in text or video format, projects, quizzes, etc.) many times, in various settings or courses, even share them with their colleagues. Portability enables instructors to reuse their assets across many different platforms or LCMSes.

\section{Implementing e-assessment}

In this section we propose some practical ways to teachers wishing to use e-assessment in their educational practice. Of course, some ways may not be appropriate for all majors but it is up to the teacher to adapt them to their course, or even, try something different.

\section{First option: Use an LMS to automate the handling of assessments and quizzes}

Popular LMSes incorporate testing modules which enable instructors to design and post tests online. Moodle for example, supports a wide variety of quizzes (depicted in Figure 1), in contrast to most LMSes and MOOC platforms. In fact, most MOOCs stick to Multiple Choice questions (MCQ).

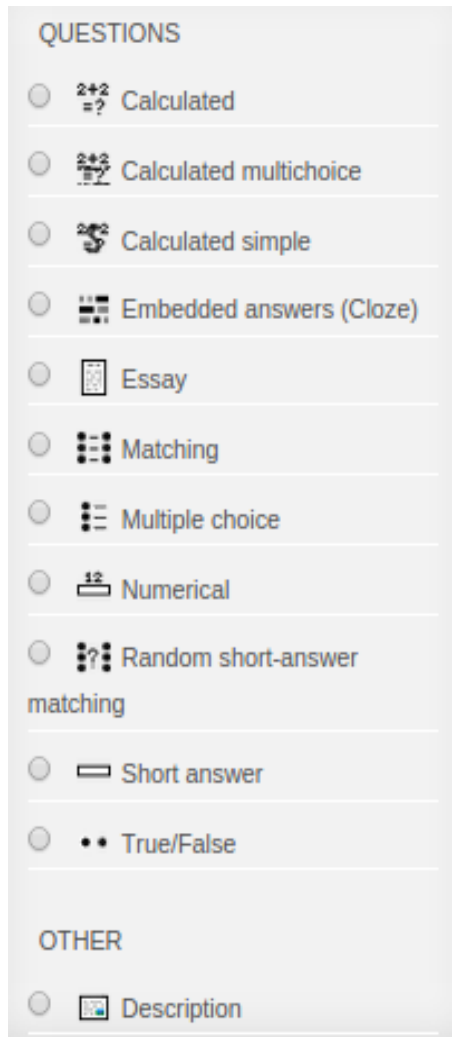

Figure 1 - - Moodle supports a wide variety of quizzes

\section{Second option: Use quiz creation software}

If installing an LMS seems difficult, there is a good alternative: use specific quiz creation software. One of the most famous applications in this area is Hot Potatoes. The Hot Potatoes suite includes six applications, enabling teachers to create interactive multiple-choice, short-answer, jumbled-sentence, crossword, matching/ ordering and gap-fill exercises for the Web. Hot Potatoes is freeware but not open-source. Teachers 
can upload their quizzes to hotpotatoes.net and can even export a SCORM object which is portable (Hot Potatoes, 2015).

\section{Third option: Use a spreadsheet application to create quizzes}

It is possible and relatively easy to create quizzes using spreadsheet applications such as Powerpoint or Calc. In addition, there is a number of commercial applications that facilitate this task (https://www.youtube.com/watch?v=UssuI0mY6RI; https://www.youtube.com/watch?v=BVpquBe7auQ).

\section{Fourth option: Use peer assessment}

Peer assessment has been used in education since many years. It is the best option for humanities courses where the answer is not a plain number or a single choice of an MCQ, but an essay. Advanced natural language analysis and artificial intelligence technologies are needed for e-assessment; instead, human peer assessment solves this problem, without the need for technological support. In fact, peer assessment is widely used by Coursera, a major MOOC provider, not only in humanities but also in technological courses.

\section{Fifth option: Put the computer find the errors}

In many engineering classes students learn to design things such as electronic systems or control systems or aeronautical systems or computer hardware systems or code or engines or buildings etc. Many of these design applications incorporate a "Design Rules Checker" (or something similar). In programming language courses the Compiler locates and enumerates all syntactical errors (Farrow and King, 2008; Andreatos, 2009). So why not use the design platform to find the errors automatically?

\section{Example:}

In a MOOC teaching the Python programming language, the students would upload their code in an online compiler called the "Autograder", which would check the produced output by the student's code and compared it to the desired output (Figure 2).

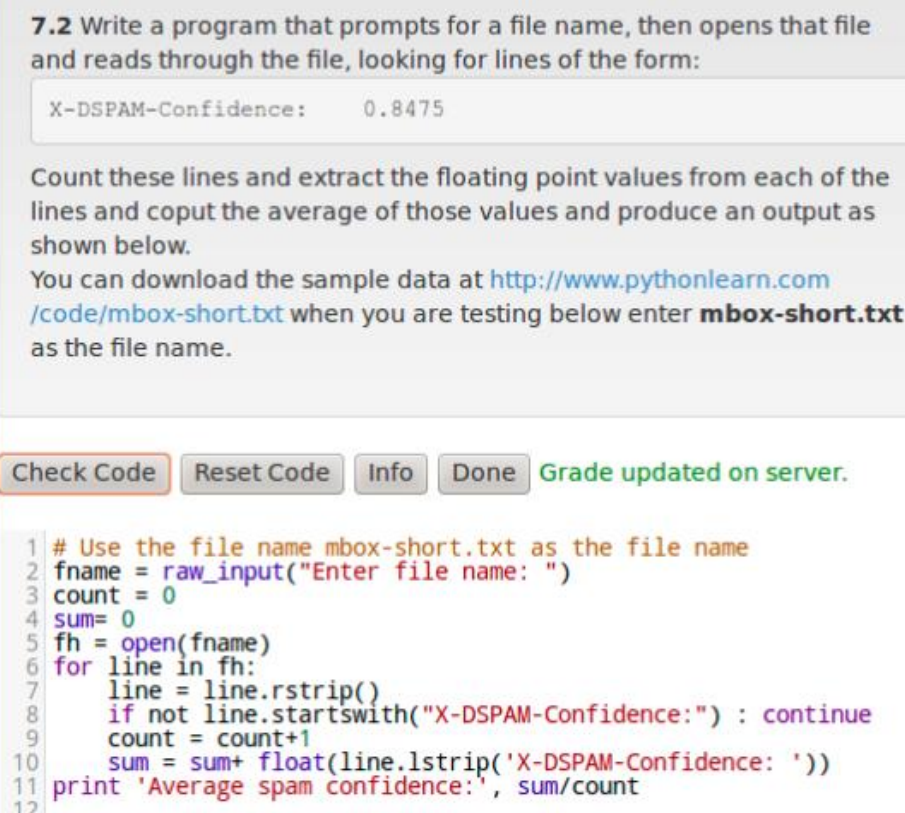

Figure 2 - - The "Autograder" checks the produced output and compares it to the desired output 


\section{Sixth option: One picture is worth a thousand of words}

In some courses students have to design something that will end up in a $2 \mathrm{D}$ or $3 \mathrm{D}$ design or product, e.g. a logo or a piece of furniture or building. The experienced teacher can easily assess the result by looking at it carefully and checking against the given specifications.

\section{Conclusion}

In this paper we have presented some simple ways which will help teachers to move towards e-assessment. This is very crucial nowadays, because the Web 2.0 tools available today, push traditional face-to-face education towards blended learning settings, for a number of reasons:

$1 /$ Internet is available in most homes of the western world;

2/ Students have Internet access at school, home and elsewhere, by means ot their portable devices such as smart phones and tablets.

$3 /$ There is a number of freely available Web 2.0 tools facilitating e-Learning and online team work.

Hence, sooner or later, many teachers will need to create online tests and quizzes or transfer exiting ones online. We hope that the methods proposed herein constitute a good starting point.

\section{References}

Althawadi, M., Ligawen, S., Videz, R. and Cadiente, D. (2015) Transitioning Language Learning Through Blended Solution. To appear in the Proceedings of the $5^{\text {th }}$ International e-Learning Conference, Bahrain.

Andreatos, A. and Doukas, N. (2006). e-Xaminer: Electronic Examination System, Proceedings of the 3rd WSEAS / IASME International Conference on Engineering Education, Vouliagmeni, Athens, Greece.

Andreatos, A. (2009). Electronic exams for the 21st century. Lecture Notes in Electrical Engineering, 2009, 27(5), 383- 390. DOI:10.1007/978-0-387-84814-3_38. http://www.springer.com /gp /book/ 9780387848136. Retrieved 18/2/2015.

Farrow, M. and King, P. J. B. (2008) Experiences With Online Programming Examinations. IEEE Transactions on Education, VOL. 51, NO. 2, MAY 2008, pp. 251-255.

Hatziapostolou, T. and Paraskakis, I. (2009). Effective Provision of Formative Feedback in an eLearning Environment. In Proceedings of ECEL 2009.

Hot Potatoes (2015). Retrieved 30 June 2015 from: https://hotpot.uvic.ca.

Powerpoint quiz creation (2015). Retrieved 30 June 2015 from: https://www.youtube.com/watch?v=hbWxKPV06ps.

Henderson, A. J. (2003). The E-Learning Question and Answer Book. AMACOM, New York, NY.

Wikipedia: Learning_management_system (2015). Retrieved 30 June 2015 from: https://en.wikipedia.org/wiki/Learning_management_system. 